\title{
CATENIPORA QUADRATA (FISCHER-BENZON, 1871) В СИЛУРЕ БАЛТОСКАНДИИ
}

Catenipora quadrata относится к наиболее трудно распознаваемым видам катенипор, установленным в прошлом столетии, так как прнзнаки вида были охарактеризованы Р. Фишер-Бензоном только несколькими строками и изображены на двух рисунках, один из которых очень мелкого масштаба (Fischer-Benzon, 1871, табл. III, фиг. 6, 7). Из последнего, однако, становится понятно, что под видовым названием quadrata Р. Фишер-Бензон подразумевал катенипоры с мелкими, малоокругленными кораллитами, ввиду чего как сами кораллиты, так и сложенные ими петли имеют несколько угловатую форму. Изучение богатого материала катенипор с о-ва Готланд показало, что из всех известных в Балтоскандии цепочечных кораллов такому диагнозу удовлетворяют только перечисленные ниже формы, в большом количестве встречаемые в мергелях Висбю. Незнание, однако, признаков $C$. quadrata, и в частности его изменчивости, привело к тому, что в течение столетия было установлено много видов-синонимов и не только в разных районах Балтоскандии (Клааманн, 1961, 1966; Stasinska, 1967), но и в других регионах (см. синонимику). Незначительные различия в основных признаках вида - в размерах кораллитов, конфигурации лакун и характере септального аппарата - не выходят за рамки установленной нами внутривидовой изменчивости $C$. quadrata. Наглядно демонстрирует это таблица настоящей статьи, в которой приведены количественные признаки ряда экземпляров $C$. quadrata и видов-синонимов. Морфология рассматриваемого вида и результаты проведенной ревизии более подробно освещены в нижеследующем описании.

\section{Catenipora quadrata (Fischer-Benzon, 1871)}

Табл. I, фиг. $1-4$; табл. II, фиг. $1-4$; рис. 1 KO!)

1826. Catenipora escharoides - Goldfuss, табл. 25, фиг. 4а (толь-

1871. Halysites quadratus nov. spec. - Fischer-Benzon, с. 21, табл. III, фиг. $6,7$.

1915. Halysites quadratus Fischer-Benzon - Yabe, c. 33 (9), табл. $\mathrm{V}$ (I), фиг. $1-2$.

1915. Halysites parallelus Fr. Schmidt - Yabe, c. 34 (10), табл. VI (II), фиг. $1-2$. 


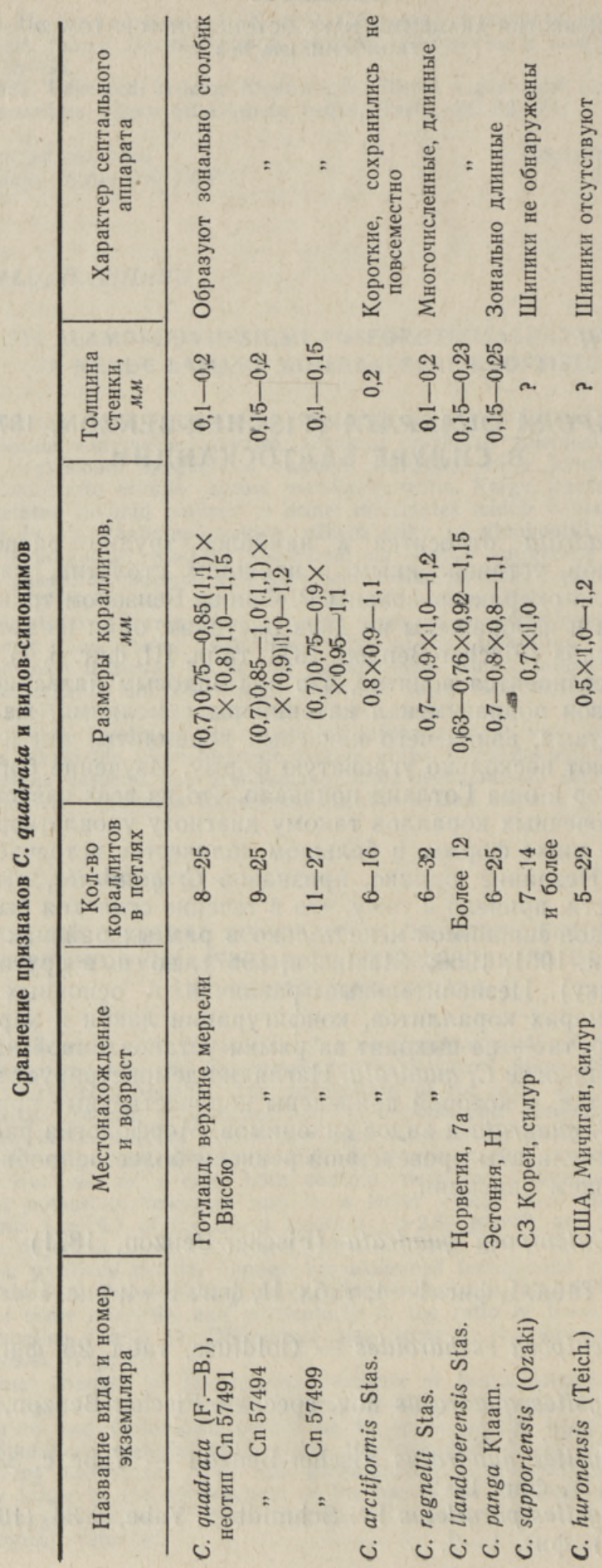


1934. Halysites sapporiensis sp. nov. - Ozaki in: Shmizu, Ozaki et Obata, c. $77-78$, табл. XVII, фиг. 4 ; табл. XVIII, фиг. 3, 4.

1937. Halysites huronensis n. sp. - Teichert, с. 135, табл. Х, фиг. 1.

1955. Catenipora quadrata (Fischer-Benzon) - Buehler, c. 41.

1955. Catenipora sapporiensis (Ozaki) - Buehler, c. 60-61.

1955. Catenipora huronensis (Teichert) - Buehler, c. 64.

1957. Quepora huronensis (Teichert) - Hamada, c. 399.

1957. Quepora sapporiensis (Ozaki) - Hamada, c. 399.

1961. Catenipora panga sp. n. - Клааманн, с. 52-53, табл. IX, фиг. $5,6$.

1966. Catenipora panga Klaamann - Клааманн, с. 52-53, табл. XIV, фиг. $7,8$.

1967. Catenipora arctiformis n. sp. - Stasinska, c. 42-43, табл. I, фиг. 2, рис. 13 в тексте.

1967. Catenipora llandoverensis n. sp. - Stasinska, c. 51, табл. II, фиг. 3,4 .

1967. Catenipora quadrata (Fischer-Benzon) - Stasinska, c. 53, табл. III, фиг. $3,4 \mathrm{a}$.

1967. Catenipora regnelli n. sp. - Stasinska, с. 52, табл. II, фиг. 2.

Г ол отип. Fischer-Benzon, 1871, табл. III, фиг. 6, 7. Из эрратического материала в Слехкасе (Schleck) у р. Вянта в Латвии. Утрачен.

Не отип. Cn 57491, табл. I, фиг. 1, 2 настоящей работы. Готланд, Снэкъярдсбаден 1. Венлок, верхние мергели Висбю. Принят за неотип здесь.

Д и а гноз. Catenipora с мелкими кораллитами размером $0,75-0,9 \times$ $\times 1,0-1,2$ мм. Из-за малой выпуклости боковых стенок кораллиты кажутся слегка угловатыми. Септальные шипики хорошо развиты, при слиянии могут образовывать столбик в центре кораллита.

О п и с ани е. Полипняки небольших и средних размеров, в поперечнике до 150 мм и высотой до 50-60 мм. На поверхности колонии лакуны кажутся угловатыми, но в шлифах их контуры смягчаются. Наибольший поперечник лакун колеблется между $3-12$ мм, ширина $-1,5-5$ мм. Они окружены $9-25$ мелкими плоскими кораллитами, угловатая форма которых особенно заметна на поверхности полипняка. По мере уменьшения толщины стенки угловатость кораллитов становится контрастнее. Обычные размеры кораллитов $0,75-0,9 \times 1,0-1,2$ мм. Стенки однородного строения, толщина преобладает около 0,15 мм. У экземпляров хорошей сохранности можно различить в стенке тонкий эпитекальный слой поперечно-волокнистой структуры и уловить различия в микроструктуре скелетного вещества как в местах слияния кораллитов, так и в их боковой части (рисунок). Днища тонкие, неправильно изгибающиеся, с интервалом 0,15-0,5 мм. Септальные шипики длинные, грубые и нередко сливаются в центре кораллита, образуя столбик. В распределении септ, а следовательно, и в развитии столбика наблюдается зональность. Это говорит о том, что у C. quadrata возможны и поперечные разрезы с небольшим количеством шипиков или даже без них (табл. I, фиг. 4; табл. II, фиг. 1).

Из менчи вость. Особенно неустойчива у C. quadrata морфология лакун. Наряду с небольшими угловатыми лакунами, которые составляют скорее не правило, а исключение, бросаются в глаза крупные и заметно округленные. Причем последние занимают центральную, наиболее выпуклую область полипняка (табл. II, фиг. 1), а маленькие и узкие - периферические его части. В отдельных полипняках кораллиты 


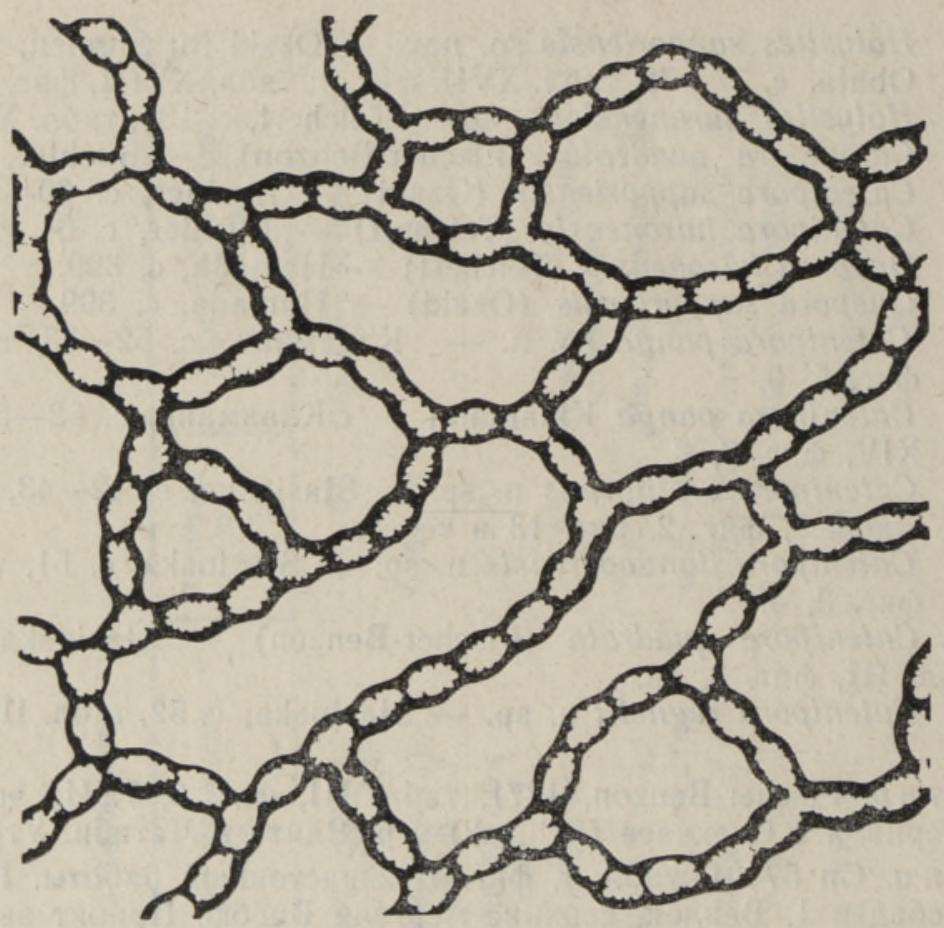

Экз. Сп 57493. Готланд, Иревикен 1. Верхние мергели Висбю. Поперечный разрез, $\times 5$. Стенки между смежными кораллитами (обозначены точками) по своей микроструктуре нередко отличаются от боковых.

собраны в небольшие округленно-полигональные петли, подобно верхнелландоверийским видам Catenipora elegans (Fisch.-Benz.) или C. ехіlis Eichw. В трактовке А. Стасиньской (Stasinska, 1967) всем подобным различиям присвоено видовое значение.

В небольших пределах изменяются и величина и форма кораллитов. У неотипа отчетливо видно, что наибольшая угловатость кораллитов приходится на те участки полипняка, где толщина стенки наименьшая (табл. I, фиг. 1). С увеличением последней несколько увеличивается выпуклость кораллитов, а тем самым и ширина, в результате чего продольный и поперечный диаметры кораллитов почти уравниваются $(1,0-$ 1,1 мм). Параллельно с тем почти во всех полипняках прослеживается и некоторое уменьшение ширины кораллитов до $0,75-0,8$ мм; это относится прежде всего к недостаточно сформировавшимся цепям кораллитов внутри наиболее крупных петель.

С равнение. Основное расхождение с первоописанием касается размеров кораллитов. Р. Фишер-Бензоном указывается $0,6-0,7 \times 0,8$ мм

\section{ТАБЛИЦА I}

Фиг. 1, 2. Неотип Cn 57491. Готланд, Висбю, Снэкъярдсбаден 1. Венлок, верхние мергели Висбю. Поперечный и продольный разрезы, $\times 5$. В левом нижнем углу фиг. 1 видно, что угловатый габитус кораллитов более четко выражен при наименьшей толщине стенки. С увеличением последней поперечный срез висцеральной полости кораллитов заметно округляется, ввиду чего кораллиты кажутся более выпуклыми (центр снимка). Фиг. 3, 4. Cn 57492. Готланд, Ликерсхамн 1. Верхние мергели Висбю. Продольный и поперечный разрезы, $\times 5$. 

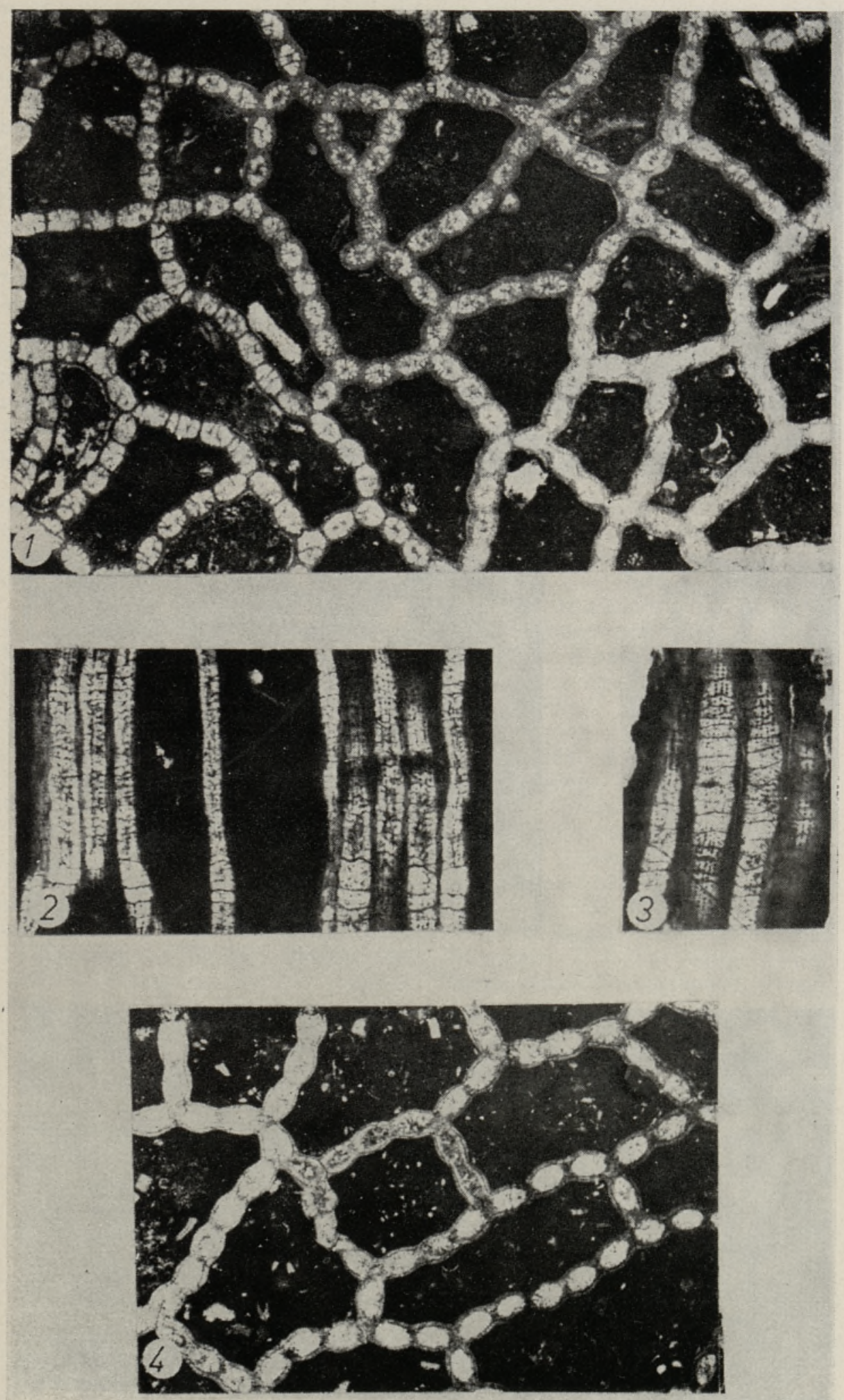

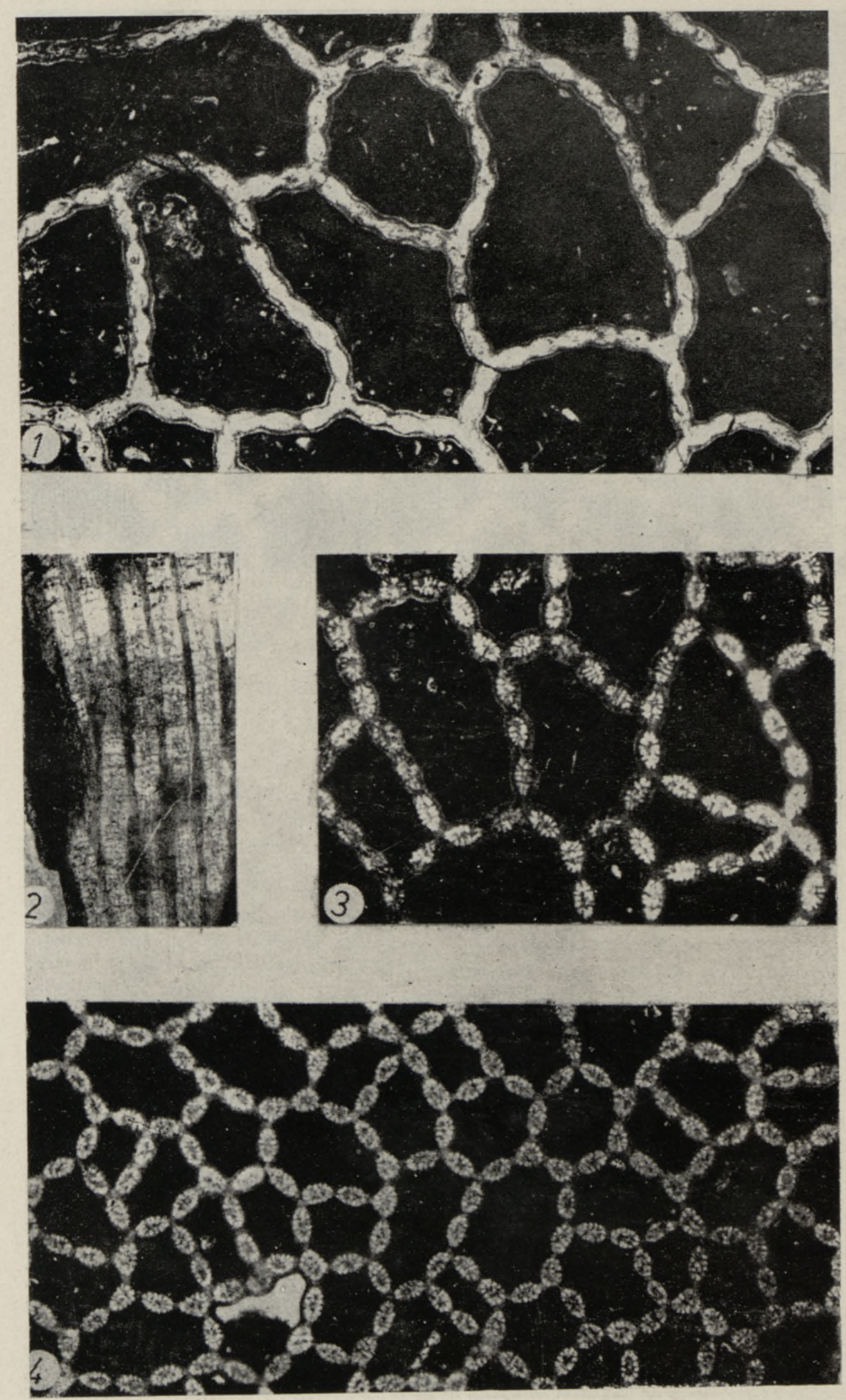
против $0,75-0,9 \times 1,0-1,2$ мм по нашим замерам. Это различие можно объяснить тем, что автором вида приведены не внешние размеры кораллитов, а поперечники их внутренних полостей. Подобный стиль измерения был характерен для палеонтологических работ прошлого столетия.

В трактуемом нами объеме $C$. quadrata больше всего напоминает C. jarviki Stasinska и C. escharoides Lamarck. Первый из них имеет более мелкие кораллиты (признак всегда выдержанный), никогда не достигающие свойственных $C$. quadrata размеров, и иной габитус кораллитов и лакун. C. escharoides совершенно не отличим по характеру септального аппарата, но обладает более крупными и округленными кораллитами.

По вышеприведенной характеристике с признаками $C$. quadrata полностью сходятся установленные А. Стасиньской (Stasinska, 1967) признаки C. arctiformis, C. llandoverensis и C. regnelli из силура Норвегии и о-ва Готланд, а поскольку все они происходят из одного и того же стратиграфического уровня, нет необходимости присваивать им самостоятельность. То же относится и к $C$. panga Klaamann.

Р а сп ростр анени е. Верхи лландовери - низы венлока Балтоскандии: слои 7а Норвегии; нижние (редко) и верхние мергели Висбю и низы слоев Хёгклинт о-ва Готланд; адавереский и яаниский (ниже подошвы ниназеской пачки) горизонты Эстонии. Кроме того, известен из силура Северной Америки и СЗ Кореи.

Местонахождение. О-в Готланд. Нижние мергели В и с б ю: Висбю, Густавсвик, 3 экз., колл. В. Яануссона (1967); Висбю, Коппарсвик (по данным А. Стасиньской). Верхние мергели В исб ю: Халл, Халлс Хук 1, 12 экз., колл. автора (1975); Хангвар, Хэфтингсклинт 1, 3 экз., колл. Б. Неумана (1966); Хангвар, Иревикен 1, 4 экз., колл. Х. Нестора (1966) и К. Ларссона (1974); Стенчюрка, Ликерсхамн 1, 14 экз., колл. Х. Нестора (1966), Б. Неумана (1966), Н.-М. Ханкена (1974), К. Плейела (1974) и автора (1975); Стенчюрка, Балсклинт 1, 1 экз., колл. Г. Лильевалла (1911); Стенчюрка, Стенчюрке Хук, 2 экз., колл. К. Ларссона (1974); Луммелунда, Лусклинт 1 (по данным А. Стасиньской); Вескинде, Кронвикен 1, 2 экз., колл. Э. Ярвика (1974); Бисбю, Корпклинт 1, 8 экз., колл. автора (1975); Висбю, Снэкъярдсбаден 1, 3 экз., колл. В. Яануссона (1967); Висбю, Ваттенфаллет, соответственно $1,7-1,9 ; 3,10 ; 6,5$ и $9,2-10,0$ м выше уровня моря, колл. Г. Лильевалла (1908); Вестерхейде, Хёгклинт 1, 4 экз., колл. автора (1975). Н из ы слоев Хёгклинт: Вестерхейде, Лиллклинт 1, 11 экз., колл. Б. Неумана (1966).

\section{ТАБЛИЦА II}

Изменчивость морфологии петель Catenipora quadrata от крупных вытянутых (фиг. 1) до небольших округленно-полигональных (фиг. 4). На фоне этой значительной изменчивости внешнего облика колонии количественные признаки отдельных кораллитов остаются постоянными. Фиг, 1, 2. Cn 57499. Готланд, Ликерсхамн 1. Верхние мергели Висбю, $\times 5$. Фиг. 3. Сn 56797. Готланд, Кронвикен 1. Нижние мергели Висбю, $\times 5$. Фиг. 4. Сп 20003. Готланд, Висбю Нурдерстранд. Нижние или верхние мергели Висбю, 


\section{ЛИТЕРА Т У Р А}

К л а а м ан н Э. 1961. Табуляты и гелиолотиды венлока Эстонии. Тр. Ин-та геол. АН ЭССР, 6, 69-1'12.

Кл а а м анн Э. 1966. Инкоммуникатные табуляты Эстонин. Таллин, с. 121.

B u ehler, E. J. 1955. The morphology and taxonomy of the Halysitidae. Bull. Peabody Mus. Natur. Hist., 8, 79.

$\mathrm{F}$ is cher-Benzon, R. 1871. Mikroskopische Untersuchungen über die Struktur der Halysites-Arten. Abh. Ges. Naturwiss., Ser. 2, 5, 9-23.

Go $1 \mathrm{~d}$ f u s s, G. A. 1826. Petrefacta Germaniae, Th. 1. Düsseldorf, S. 1-76.

$\mathrm{Ham}$ a da, T. 1957. On the classification of the Halysitidae, I, II. J. Fac. Sci. Univ. Tokyo, Ser. 2, 11, 393-430.

Oz a ki, K. 1934. Corals, In: Shimizu, S., Ozaki, K., Obata, T. Gotlandian Deposits of Northwest Korea. J. Shanghai Sci. Inst., Ser. 2, 1, 62-78.

Teichert, C. 1937. Ordovician and Silurian faunas from Arctic Canada. Repts 5 th Thule Exped., 1, 1-167.

$\mathrm{Y}$ a be, H. 1915. Einige Bemerkungen über die Halysites-Arten. Sci. repts Tohoku Imp. Univ., Ser. 1, 4, 25-38.

Ннститут геологии

Академии наук Эстонской ССР
Поступила в редакцию

14/I 1977

\section{E. KLAAMANN}

\section{CATENIPORA QUADRATA (FISCHER-BENZON, 1871) BALTOSKANDIA SILURIS}

Revisjoni tulemusena on täpsustatud liigi morfoloogiat, kindlaks tehtud tunnuste muutlikkuse piirid ja sünonüümsed liigid ning fikseeritud liigi levik Baltoskandia siluris (ülemländouver - alamuenlok). Gotlandi saare ülemistest Visby merglitest on valitud neotüüp.

\section{E. KLAAMANN}

\section{CATENIPORA QUADRATA (FISCHER-BENZON, 1871) IM SILUR VON BALTOSCANDIA}

Auf Grund der taxonomischen Revision wurde die stratigraphische Verbreitung Oberes Llandoverium-Unteres Wenlockium - der bisher nur aus erratischem Material bekannten Catenipora quadrata bestimmt. Aus dem Oberen Visby-Mergel von Gotland, wo die Art am häufigsten vorkommt, hat man den Neotypus gewählt (Taf. I, Fig. 1, 2) Die durchgeführte Revision stellte die synonymischen Arten und die Veränderlichkeit der Form und Größe der Ketten und Koralliten fest (Taf. II, Fig. 1, 2). In korrigierter Form lassen sich die wichtigsten Merkmale von C. quadrata zu folgender Diagnose zusammenfassen; Catenipora mit kleinen Koralliten, 0,75-0,9 ×1,0-1,2 mm im Durchmesser. Da die Korallitenwand an den Seiten ziemlich flach ist, erscheinen die Koralliten etwas eckig, insbesondere an der Oberfläche des Stockes und wo die Wände dünner sind. Die Böden dünn und wellenförmig, Intervall $0,15-0,5 \mathrm{~mm}$. Septaldornen zonal zahlreich entwickelt, lang und in der Mitte der Koralliten zu einer unterbrochenen Kolumella vereinigt. 